\title{
Surveillance for Prevention \& Identification of GI IIIness Outbreaks Associated with Swimming Pools
}

\author{
Sheharyar Minhas ${ }^{* 1,2}$ \\ ${ }^{1}$ Rollins School of Public Health, Emory University, Bensalem, PA, USA; ${ }^{2}$ Nazareth Hospital, Philadelphia, PA, USA
}

\section{Objective}

To prevent and identify gastrointestinal outbreaks due to swimming pools using a two-part surveillance system i) Model Aquatic Health Code (MAHC) Guideline Survey and ii) syndromic surveillance

\section{Introduction}

Swimming in contaminated pools can cause gastroenteritis from water contaminated by viruses, bacteria, or parasites. Germs that cause gastroenteritis are shed in feces of infected persons, and easily spread to uninfected persons swimming in pools. Symptoms of gastrointestinal illness can include nausea, vomiting, watery or bloody diarrhea, and weight loss. Common causes of swimming-related gastroenteritis included viruses (norovirus), parasites (giardia, cryptosporidium), and bacteria (Escherichia coli, Shigella). Cryptosporidium is most common agent associated with swimming pool outbreaks. In 2011-2012, public health officials from 32 States reported 90 swimming-pool associated outbreaks to CDC's Waterborne Disease and Outbreak Surveillance System (WBDOSS). These 90 outbreaks resulted in 1,788 cases, 95 hospitalizations, 1 death. $52 \%$ of these outbreaks were caused by Cryptosporidium.

\section{Methods}

Literature search was conducted using published peer-reviewed articles via PubMed and Internet websites including, CDC and U.S. consumer product safety commission, Agency for toxic substance and disease registry. Statistical data on GI illness outbreaks associated with swimming pools prevalence and outcomes were also reviewed. Current surveillance methods used for detecting prevalence of waterborne disease outbreaks are based on examples from Ohio and Nebraska to determine approaches and effectiveness of the systems.

\section{Results}

Survey and Education Packet -

Distribute a survey with questions about current MAHC guideline adherence and MAHC educational packets that include the incident response guidelines and the water contamination response log

Strengths: Low cost, simple, and acceptable

Limitations: Not timely event reporting

Event Reporting -

Develop a website for reporting contamination events based on the water contamination response $\log$

Strengths: Timely reporting

Limitations: Complex to setup and maintain, moderate cost, and may not be acceptable

\section{Pool Inspections -}

Require pools to undergo periodic inspections to monitor adherence to MAHC guidelines

Strengths: Complete and representative

Limitations: Complex, expensive, not timely event reporting

The current system is based on state reporting to the CDC through the paper-based reporting waterborne disease outbreaks surveillance system (WBDOSS), and the National Outbreak Reporting System (NORS), an electronic reporting system in place since 2009
CDC uses waterborne disease outbreak surveillance data to

o identify the types of etiologic agents, and settings associated with outbreaks

o evaluate the adequacy of regulations to promote healthy and safe swimming

$\circ$ establish priorities to improve prevention, guidelines, and regulations at the local, state, and federal levels

The WBDOSS is not sufficient to capture early detection and reporting of AGI outbreaks. We recommend the these surveillance approaches:

Syndromic surveillance of WBD outbreaks to capture early outbreaks of diarrheal, and as many suspected cases as possible in a timely manner

Sentinel surveillance at specific healthcare facilities in the proximity of swimming pools where outbreaks can occur

Active Lab-based surveillance would offer more robust and complete analysis of the prevalence and incidence of acute GI illness outbreaks in the State

\section{Conclusions}

Our study concluded that state health department should begin a two-part surveillance system: i) distributing MAHC guideline surveys \& education packet; ii) syndromic surveillance system for outbreaks. MAHC Guideline Survey and Education Packet would be cost effective to educate pool operators on current MAHC guidelines and gather baseline data on adherence to MAHC guidelines for responding to contamination events. Afterwards, once baseline data is gathered and awareness of the MAHC guidelines is established, the state health department can determine if event reporting or pool inspections are necessary to increase either the timeliness or representativeness of the surveillance system. Syndromic surveillance would be the most timely and sensitive surveillance system. This is important to achieve health department's goal of early outbreak detection. Both predictive value and data quality are limitations of syndromic surveillance system. Acute gastrointestinal illness is also caused by sources other than pool contamination which can cause false positives.

\section{Keywords}

gastrointestinal outbreaks; swimming pools; model aquatic health code (MAHC); syndromic surveillance

\section{Acknowledgments}

To Rollins School of Public Health at Emory University in Atlanta and Department of Medicine at Nazareth Hospital in Philadelphia.

\section{References}

1-CDC. Protracted Outbreaks of Cryptosporidiosis Associated With Swimming Pool Use --- Ohio and Nebraska, 2000 MMWR 2001; 50(20); 406-410. http://www.cdc.gov/mmwr/preview/mmwrhtml/ $\mathrm{mm} 5020 \mathrm{a} 3 . \mathrm{htm}$

2-CDC. Outbreaks of Illness Associated with 2-Recreational Water United States, 2011-2012 MMWR. 64(24); 668-672. http://www.cdc. gov/mmwr/preview/mmwrhtml/mm6424a4.htm?s_cid=mm6424a4_w 


\section{ISDS 2018 Conference Abstracts}

3-CDC. The Model Aquatic Health Code. August 2015. http://www.cdc. gov/mahc/index.htm

4-CDC. (n.d.) Decoding the MAHC: The Model Aquatic Health Code. Retrieved from https:/www.cdc.gov/healthywater/pdf/swimming/ pools/mahc/decoding-the-mahc.pdf

5-CDC. (2016). Fecal Incident Response Recommendations for Aquatic Staff. Retrieved from https://www.cdc.gov/healthywater/swimming/ pdf/fecal-incident-response-guidelines.pdf

6-CDC. (n.d.) Water Contamination Response Log. Retrieved from https://www.cdc.gov/healthywater/pdf/swimming/pools/watercontamination-response-log.pdf

7-CDC. (2016). Model Aquatic Health Code Aquatic Facility Inspection Report. Retrieved from https:/www.cdc.gov/mahc/pdf/mahc-aquaticfacility-inspection-report.pdf

\section{*Sheharyar Minhas}

E-mail: sminhas7@yahoo.com 